\title{
Letrozole as upfront endocrine therapy for postmenopausal women with hormone-sensitive breast cancer: BIG 1-98
}

Dieter Koeberle $\cdot$ Beat Thuerlimann

Published online: 13 December 2007

(C) Springer Science+Business Media, LLC. 2007

Erratum to: Breast Cancer Res Treat (2007) 105(Suppl 1) DOI 10.1007/s10549-007-9700-y

Due to an oversight, Financial Disclosure of the Authors in the above referenced supplement was not published as required. All authors have acknowledged and signed a

statement of Financial Disclosure/Conflict of Interest and certify that no honoraria for the work therein were received.

The online version of the original article can be found under doi:10.1007/s10549-007-9700-y.

D. Koeberle $(\bowtie) \cdot$ B. Thuerlimann

Department of Internal Medicine, Division Oncology/

Hematology, Kantonsspital, 9007 St. Gallan, Switzerland

e-mail: dieter.koeberle@kssg.ch 